\title{
A não-ação como terreno fértil para o trabalho do ator
}

Denis Marleau e Stéphanie Jasmin*

...re-explorando no passado...pequenas cenas claras... sobretudo passeios...toda sua vida a passar...todos os dias de sua vida... dia após dia...dois, três passos, depois pára...os olhos no vazio... depois faz ainda dois, três...pára e o vazio de novo...assim segue... a deriva...dia após dia...ou às vezes ela chora.....sozinha com sua recordação...desde os cueiros...do chorar nos cueiros...talvez não... não indispensável a vida...a sobrevida...soluçar um ponto é tudo. S. Beckett, Não Eu, 1972.

- Você não deve emitir uma única voz. Em Maeterlinck, tudo é polifonia de linguagem, é palavra múltipla. É através da voz que você poderá colocar em órbita os conflitos interiores que atravessam o personagem;

- O que desenvolve uma tensão é aquilo que não podemos prever;

- Com sua mímica facial e sua voz não comente o que se passa, é preciso aprender a ser neutro, tornar-se um receptáculo neutro;

- Na criança, há uma maneira de ser no mundo, sem julgamento, uma capacidade de entrar em si, de se ausentar;

- Para fazer entender o pensamento de Maeterlinck, é preciso começar por jogar até o fundo as questões do texto que não são jamais retóricas, porque sem elas não há mais debate interior;

- Sensações de torpor, de angústia e inquietude. Para tal, procure-as na dimensão exata e concreta. O personagem em Maeterlinck é um conjunto de sensações, freqüentemente contraditórias, reunindo o frio e o calor, o determinado e o indeterminado, a luz e a obscuridade...;

- O texto expressa um pensamento inquieto e em movimento. Ele não é um discurso de conhecimentos e de saberes, e nesse momento você atua como se soubesse tudo, como se compreendesse tudo o que se passa em você e a seu redor;

- É preciso que você se ausente mais quando você fala;

- Deixe ressoar os silêncios em você;

- Que cada frase, cada segmento, que fala de elementos ligados à natureza se transforme em experiência visual, tátil, auditiva e não em informação. Senão tudo se torna boletim meteorológico;

- Dizer uma frase é procurá-la;

-A pontuação em Maeterlinck se compõe quase que exclusivamente de suspensão, interrogações e exclamações. Três maneiras de existir na frase que não podem ser confundidas;

- Quando o discurso não é suspenso por um estado, no caso de incerteza, ele não faz sentido, não se entende;

\footnotetext{
* Tradução: Marta Isaacsson
} 
- Com os silêncios e pausas, que não estão inscritos na partitura, você deixa entrar os outros pensamentos que acabam parasitando sua expressão;

- Algo de exterior parece agir sobre o personagem maeterlinckiano e isso acontece por pequenos toques, por impregnação. Deixe sua visão, sua pele, seu ouvido se impregnar do mundo que a linguagem coloca em órbita. Desta maneira, você poderá talvez experimentar novos registros de presença;

Essas são algumas das orientações de atuação dadas por Denis Marleau quando do estágio que ele dirigiu em agosto e setembro de 2004; um estágio que se dirigia a quinze jovens atores oriundos de cinco países europeus e que se intitulava Maeterlinck: presença / ausência do ator. Convidado por Franco Quadri para esta primeira edição do Projeto Thierry Salmon, este programa de formação tem como inestimável vantagem a duração (dois meses) e a efervescência estimulante provocada pela mistura de línguas e de culturas teatrais de seus participantes. O Projeto Thierry Salmon convida assim dois encenadores por edição, que oferecem estágios em paralelo, em quatro países diferentes, para se reencontra no final em um quinto país. Este ano, Jan Fabre, o outro "mestre" convidado, trabalhava com seu grupo na Espanha e em Portugal, enquanto Denis Marleau desenvolvia seu estágio na Itália e Bélgica. Ao final, os dois grupos se encontraram em Limoges, depois em Roma onde encerraram a aventura. Esta experiência foi uma das mais interessantes para Denis Marleau; na realidade, ter a ocasião de realizar uma pesquisa teatral com atores, fora do quadro acadêmico habitual, com duração bastante longa e sem a finalidade de produção ao final do processo, é raro e único deste projeto.

Denis Marleau escolheu então abordar textos do autor simbolista belga do qual tinha montado duas peças: Interior em 2001 e depois Os Cegos em 2002, uma "fantasmagoria tecnológica” que viaja por todas as partes do mundo desde sua criação. Nesta, os atores não estão presentes ao vivo sobre a cena, mas por projeção em vídeo de seus rostos sobre máscaras e sua voz que instala uma relação de estranhamento com o espectador. Peça ao menos emblemática de um teatro estático e sem ação que é aqui o mais reduzido possível (os cegos imobilizados na obscuridade esperam seu guia), ela constrói, todavia, uma longa e lenta catarsis que termina com a chegada da morte... Este trabalho foi muito significativo no desenvolvimento de Denis Marleau que buscou responder a uma questão impossível através de meios técnicos modernos, utilizando um dispositivo que lembra, ao mesmo tempo, a origem do teatro (as máscaras da tragédia grega) e aquela do cinema (a fatasmagoria).

Desejoso de aprofundar esta questão da presença do ator, Denis Marleau quis então re-trabalhar Os Cegos, mas com quinze atores estagiários sobre o palco, sem recurso a outros meios cênicos, sonoros ou vídeográficos. Com eles, ele também abordou textos que ele conhecia menos: A Morte de Tintagiles ${ }^{1}$ e Peleas e Mélisandre, ${ }^{2}$ duas peças do primeiro teatro de Maeterlinck dos anos 1980. Estes textos possuem em comum uma ação mínima, traços psicológicos arquetípicos, falas de léxico simples, repetitivo e uma linguagem de vazios, completada por vazios. Para os atores, isso representa um trabalho exigente porque deixa pouca margem de manobra e de indícios para construir a interpretação. Eles devem confiar na linguagem e investir totalmente nela. Precisam procurar essa máscara neutra a qual aspira o espectador, sobre a qual tudo pode aparecer: das menores sensações as mais 
violentas angústias. E ter o sentimento que cada palavra é uma descoberta, um nascimento no mundo.

Assistente de Denis nessa aventura, eu gostaria de dividir um momento entre muitos outros interessantes deste estágio, no momento em que o trabalho de ensaio me pareceu revelador das problemáticas que pode levar esta redução minimalista da ação para o ator e para o encenador. Posteriormente, colocarei algumas questões a Denis Marleau em vista de avaliar e de continuar a reflexão, ainda em conseqüência deste estágio.

O que eu digo? Eu me recordo...não acredito mais nisto...podemos dormir...Tudo isso não tem importância e não é possível..... Não sei mais o que penso...lhe acordamos e depois... No fundo, vejamos, no fundo, é preciso refletir...Dizemos isso, dizemos aquilo, mas é a alma que segue um outro caminho. Não sabemos tudo o que desencadeamos. Vim aqui com minha pequena lamparina...Ela não se apaga apesar do vento na escada....No fundo, o que se pode pensar disso? Há muitas coisas que não são fixas...M. Maeterlinck, A Morte de Tintagiles, 1804.

\section{Representar a vertigem da morte sobre a cena}

Dia 17 de setembro de 2004. Ensaio do V ato de A Morte de Tintagiles. Último ato da peça, onde em cena Ygrane tensa e perdida, a procura de seu irmão pequeno, Tintangiles, desaparecido durante a noite. Ela escuta sua pequena voz que trespassa fragilmente uma porta enorme e impossível de abrir. Tingagiles a suplica de abri-la muito rápido, porque Ela se aproxima implacavelmente e ele vai morrer. Ela é a rainha, personagem ameaçador que reina sobre todos, mas que ninguém parece ter jamais visto. Ela é a morte que vai atingir o pequeno Tintagiles, apesar dos esforços de Ygraine para abrir essa porta que a separa para sempre da criança. A estrutura da cena se articula em um diálogo de falas breves entre a criança e Ygraine, enquadrado por dois longos monólogos desta última personagem. Os pontos de suspensão dominam nitidamente os monólogos de Ygraine cujas frases como pensamentos não podem se fechar, eles são caóticos e fragmentados. Não há nenhuma ação senão as duas solidões, uma das quais está fora de cena, não se pode ver e nem tocar. É uma experiência de agonia violenta, da morte de uma criança, vivida tanto por ele quanto por sua irmã. Nada se passa, além deste drama total que é a morte.

Durante várias semanas este ato difícil é trabalhado por duas duplas de atores. Na véspera da demonstração pública de Limoges, ensaiamos em uma sala ensolarada, ligada aos ateliês de cenários do Théâtre de l'Union. Uma das duplas refez a cena. Eles tiveram o sentimento que o trabalho não parava de avançar e retroceder. Sentiam-se perdidos. Apesar de conscientes do jogo dramático não conseguiam transpor sua compreensão para a interpretação, tinham dificuldade de composição. A última pista de trabalho dada à atriz, intérprete de Ygraine, foi trabalhar a noção de delírio nos dois monólogos. Na realidade, a organização das frases e sua pontuação criam um fluxo de palavras que, por vezes se contradizem, por vezes se justapõem de maneira abrupta e descontínua. As palavras surgem nela, a surpreendem mesmo, não há

nenhuma estratégia retórica. É um pensamento bruto que circula com seus próprios elos 
alusivos e inconscientes. Denis utilizou a imagem "de um motor de trabalho que conduz uma pulsão constante” para falar do discurso de Ygraine. Ele evocou também algumas pessoas que cruzamos às vezes na rua e que entram em delírios prolixos, sozinhos em sua bolha... É preciso encontrar este impulso onde a menor palavra torna-se importante estabelecendo uma tensão extrema desde o começo da cena: "Isso fala através dela, apesar dela", diz ele. Os atores refazem a cena, mas experimentam dificuldade de se abandonar, não se sentem confortáveis com suas posições corporais. Eles estão ainda procurando e interpretando um pouco fora deles mesmos. Ao final da cena, Denis não comenta em seguida, parece refletir e procurar o que dizer. Durante longos minutos, há um silêncio, um tempo vazio. Depois, ele pede aos atores de retomar toda a cena, mas desta vez de outra maneira: em pé, lado a lado, sem mexer e o mais rapidamente possível. Os atores executam e se passa algo de fascinante. A linguagem aparece, tridimensional com toda sua clareza, sua força e sua humanidade. De repente, Denis lembra do texto Eu Não de Beckett e afirma que o dramaturgo irlandês provavelmente leu A Morte de Tintagiles... Mesma respiração ofegante, mesmo movimento do discurso, mesmos pontos de suspensão que mantém o estado de equilíbrio, sem queda e sem repouso; mesma vertigem que produz repente uma forte emoção. Ygraine começa a existir. Toda ação, todo movimento de pensamento se coloca nu, com suas modulações e suas hesitações. Todo drama de Ygraine e de Tingagiles emerge de dois corpos que se tornam rapidamente tão frágeis quando as figuras de Giacometti.

Os atores ficam reticentes, se sentem travados pelo obstáculo técnico: conseguir a rapidez de maneira virtuosa e isso, à véspera de uma demonstração pública. No dia seguinte, ensaiamos brevemente e eles estavam em crise. Acreditam precisar de mais tempo para primeiro dominar esta rapidez e depois integrar a ela a emoção, de maneira a não cair em uma interpretação mecânica, reduzida a uma performance. Mas Denis revida, dizendo que o processo não deve se fazer em dois tempos, que a emoção está inscrita no seio mesmo da partitura, em suas palavras, em sua pontuação, em seus gritos. Ygraine, por exemplo, diz que ela não sabe, ela diz que vai se esvair, ela blasfema, ela suplica, ela implora...Ygraine fala como ela respira, não há nada escondido, premeditado. A linguagem diz o que é e o que não é. Isso revela a simultaneidade, a emoção é a linguagem e vice-versa.

Após a demonstração de Limoges que confirma esta pista de trabalho, partimos a Roma para uma última demonstração pública deste estágio europeu itinerante. Os atores adquiriram mais velocidade e segurança na nova premissa de representação. E, a partir do momento em que a vertigem dos atores diante da tarefa da rapidez foi substituída pela vertigem dos personagens face à morte, sua evidência se estabeleceu. A emoção surgiu invadindo quase involuntariamente os atores e provocando uma agitação tangível na platéia. A morte sobre a cena se desenvolvia sem transformá-la em espetáculo, mas nas manifestações mais intimas. Uma tragédia sem movimento, sem ação. Somente dois atores em pé, imóveis neste drama de morte, onde os gestos são vãos e inúteis e onde as palavras permanecem como sendo a última relação com o mundo.

\section{Repercussão do estágio}


O fato de montar novamente Os Cegos, mas com um grupo de atores presentes sobre a cena modificou ou atenuou sua percepção desta peça que freqüentemente é qualificada de irrepresentável?

Há o desejo, às vezes, de retornar aos autores que efetivamente marcaram meu percurso de encenador, da mesma maneira como tenho vontade de reler os livros significativos de minha infância. É o que aconteceu com Schwitters, Beckett, Koltés e Bernhard dos quais eu reativei alguns textos através de experiências de estágio, como a Florença com Roberto Zucco ou mesmo a Montreal no contexto de reprises com A Última Banda. Com Os Cegos, eu tinha simplesmente vontade de experimentar o funcionamento da obra sobre a cena. Isso porque no caso da fantasmagoria tecnológica que realizei há quatro anos no Museu de Arte Contemporânea, não é exato dizer que foi "sobre a cena". Era mais uma instalação que englobava tanto a sala quanto a cena e que inscrevia uma prova de representação somente para o espectador e não para o ator que estava ausente. Assim, eu queria abordar a questão do tempo real e vivido em Os Cegos sobre a base de uma experiência de palco vivida pelo ator. Ao longo do estágio, pareceu-me que Os Cegos não seja assim tão irrepresentável quanto se supõe, ao contrário, que esse texto é magnificamente escrito para atores. Mas para conseguir desvendá-lo, é preciso assumir totalmente sua estrutura poética e lingüística, pois não há nada, além disso, que age no espaço, além de alguns pequenos gestos ou deslocamentos. Os atores representaram então a partitura quase integralmente de forma estática, somente com alguns movimentos de cabeça em direção ao alto ou de mãos. A esta dificuldade do texto, somei aquela dos olhos que deviam permanecer fechados durante toda a representação, o que necessitou quase duas semanas de adaptação para os alunos. Eles não podiam se mexer nem olhar o que se passava em volta deles. Isso conduzia a vertigens, a contrações ou estados de impaciência, por vezes de crise, que só desapareceram ao longo do trabalho. Em contrapartida, a escuta entre os atores ocupou toda a largura de uma grande cena e produziu algo muito intenso, uma formidável tensão na penumbra que deixava ver as silhuetas humanas e o jogo dos lábios. Assim, a obra tomou forma de um oratório onde ressoava movimentos de angústia, desespero, estados de confusão que passavam de um corpo a outro dos personagens todos em pé, imóveis cuja presença terminou por promover uma emoção perceptível na platéia. No fundo, uma tal experiência confirma que não há resposta cênica definitiva a uma obra que ela seja escrita ou não para o teatro.

\section{Quais são suas conclusões sobre a questão da presença após este estágio?}

No prolongamento de meus trabalhos sobre Bernhard, Beckett, Fosse, Maeterlinck onde abordei a cena ao mesmo tempo como artista plástico e como homem de teatro, com atores, luz, música, cenário, e novas tecnologias, tinha vontade de verificar como poderia elaborar uma prática cênica do texto maeterlinckiano recorrendo ao mínimo de artifícios. Tenho também, sem dúvida, necessidade deste tipo de espaço de trabalho, contar com atores disponíveis por um longo período para aprofundar esta pesquisa que me move desde muitos anos. Como encenador, sou obcecado pela linguagem, pela questão de como realizar a passagem do texto ao corpo e a voz. Isto porque, o que me importa no teatro é conseguir 
colocar no espaço as sonoridades do texto como matéria concreta através da expressão do ator. E, neste teatro estático da obscuridade, como pode o ator fazer ver o invisível, e mesmo "fazer escutar uma voz que fala se calando", para parafrasear Maurice Blanchot.

No fundo, a presença permanece uma questão que só pode ser enfrentada pelo caminho da voz e do corpo, não vejo como possa ser diferente. Trata-se, sobretudo, de acompanhar o ator em trajetórias às vezes aparentemente contraditórias, mas que podem promover novas modalidades de presença ou de ausência sobre a cena. Associo também a noção de presença à questão do pensamento do texto que me parece faltar sobre a cena, freqüentemente o texto nos chega aos golpes, sem luminosidade sobre sua construção, sua estrutura poética. Durante o estágio, o trabalho de mesa durou quase três semanas e percebi que os atores na sua maioria separavam completamente esta etapa daquela que se seguia no espaço. Eu lhes dizia que, para mim, é a mesma etapa que este trabalho de levantamento das estruturas de uma peça, daquilo que determina o funcionamento do personagem e de seu pensamento não devia, sobretudo, se interromper porque passamos da posição sentada à posição de interpretação em pé sobre o espaço. Na realidade, eu acredito ser preciso sempre aprofundar, sabendo que os apoios e as soluções podem também vir daquilo que nos parece longe ou fora do natural. Deste ponto de vista, eu lhes falei de Kantor que pegava a marionete ou a boneca de cera como modelo do ator vivo. Mas a dificuldade hoje é que este teatro não existe mais para os atores, eles são muito jovens para terem sido confrontados a esta experiência de um teatro entre a vida e a morte que Kantor nos revelava através de suas criações.

\section{Notas}

\footnotetext{
${ }^{1}$ Escrita em 1984.

${ }^{2}$ Escrita em 1892.
} 